\title{
PROBLEMAS LINGUÍSTICOS EN LOS ESCRITOS HIPOCRÁTICOS: EL TRATADO «SOBRE LOS HUMORES»
}

The Corpus Hippocraticum offers many linguistic difficulties. Humours, written about $400 \mathrm{~B}$. C., is the most puzzling and enigmatic among these treatises. Our aim is to study its main linguistic problems concerning structure, composition, syntax and vocabulary.

1. El Corpus Hippocraticum (C. H.), o Colección hipocrática, es un conjunto de cincuenta y tres tratados de contenido esencialmente médico que nos ha llegado atribuido a Hipócrates y a su escuela desde la antigüedad.

Los tratados hipocráticos constituyen la primera colección de textos científicos que nos ha legado el mundo antiguo. La mayoría de tales obras fue escrita entre 420 y 350 a. C., aunque algunos escritos, como Sobre la decencia y Preceptos, deben fecharse en los siglos I o II d. C., por razones de lengua y contenido.

Cuando hablamos de "tratados, escritos u obras hipocráticas» no queremos decir que hayan sido escritas por el propio Hipócrates, pues, en verdad, no estamos seguros de que ningún tratado haya salido de la mano de Hipócrates en persona.

A fines del pasado milenio y durante los primeros siglos del nuestro, algunos escritos de contenido médico diferente, pero impregnados de teorías filosóficas helenísticas, se incorporaron a la Colección hipocrática, que se formó definitivamente como un corpus cerrado alrededor del siglo x d. C., en Bizancio.

2. El contenido de tales escritos es muy diverso: los hay de tipo general, anatómicos, dietéticos, de patología general y especial, quirúrgicos, ginecológicos, etc.

La forma literaria es asimismo diversa: muy bien elaborados, como Sobre los aires, aguas y lugares, Sobre la enfermedad sagrada, Sobre las fracturas; discursos a la moda sofistica vigente a la sazón, como Sobre 
los flatos; redacciones de estilo recortado, austero, breve, conciso, como Aforismos; etc.

3. Una colección tan diferente por su contenido, forma literaria y cronología (unos escritos son de fines del siglo v a. C.; otros, los más, del siglo Iv, especialmente de su primera mitad; algunos, del I o II d. C.), plantea numerosos problemas lingüísticos' ${ }^{1}$.

La mayor parte de los tratados hipocráticos fue escrita en jonio literario y científico, diferente tanto respecto de la lengua de Heródoto, como de la lengua de las inscripciones jónicas de la época. La lengua científica de los médicos está mucho más cerca del ático que el jonio peculiar que usa Heródoto. Por ello es exagerada la postura de ciertos editores de tratados hipocráticos que se empeñan en leer, contra el testimonio de los manuscritos, formas típicamente jónicas, cuando la verdad es que en los escritos médicos que nos ocupan coexisten las formas jónicas y las áticas sin estridencia ni rechazo alguno. Empecinarse en lo contrario supone defender a ultranza hiperjonismos, yendo mucho más allá que los escritores griegos de los siglos v y Iv a. C., cuando el jonio era un dialecto vivo y de alta vitalidad. Es curioso que sean precisamente los tratados más tardíos los que ofrezcan más hiperjonismos, pues fueron redactados en un momento en que el dialecto jónico había dejado de existir hacía ya mucho tiempo.

Las peculiaridades dialectales de los tratados hipocráticos suponen bastantes dificultades fonéticas (psilosis, vocalismo, contracciones), morfológicas (sufijos especiales para la formación de sustantivos, adjetivos y verbos, preposiciones especiales, conjunciones diferentes de las del ático, ciertas partículas peculiares, etc.).

También encontramos especiales problemas sintácticos, sobre todo en el desarrollo paulatino de la subordinación, y en la persistencia estilistica de la coordinación; el abuso de la parataxis, la abundancia extrema de oraciones de relativo, etc. El orden de palabras es, asimismo, de gran interés: en los Aforismos, por ejemplo, la disposición de los miembros que componen frases cortas, breves en extremo, es, a veces, muy rebuscada, con abuso de anafóricos y catafóricos, oraciones nominales puras y ciertos juegos fónicos basados en asonancias características.

El estilo es un campo poco trabajado en este Corpus, aunque encontramos realizaciones literarias muy diferentes: desde la aforística a la so-

1 Cf. A. López Eire, «En torno a la lengua del Corpus Hippocraticum», emerita 52, 1984, pp. 325-354. 
fistica; los Aforismos y Sobre los flatos pueden servir de testimonio interesante de esos dos extremos.

La disposición de los miembros constitutivos de un tratado es también asunto pertinente a la lingüística. Se ha visto que en ciertos tratados antiguos (Sobre los aires, aguas y lugares; Sobre la medicina antigua; Sobre la enfermedad sagrada; Pronóstico; Sobre las heridas en la cabeza) forman unidades estilísticas bien definidas en que cabe distinguir un prólogo orientador, un núcleo y un epílogo, dentro del gusto arcaico por la construcción anular (Ringkomposition).

Del léxico nos hemos ocupado especialmente en lo referente a los Aforismos $^{2}$, viendo cómo surge y se especializa la lengua de los médicos para dar lugar a un corpus léxico autónomo, caracterizado en buena medida por la precisión y la exactitud.

4. Sobre los humores ${ }^{3}$ es un tratado de mediana extensión (pues sólo contiene veinte capítulos) que nos frustra de inmediato a causa de su rimbombante título, sin duda tardío. Fuera del capítulo 1 (dedicado a los humores, cómo conducirlos y lograr su revulsión) y el 8 (con instrucciones generales relativas al mismo tema), el resto no se refiere al tema que el nombre del escrito parece sugerirnos.

Fue muy apreciado por los antiguos comentaristas médicos: Baqueo, Glaucias, Paladio, Galeno, entre otros. El libro guarda gran parecido, en cuanto al contenido, con Aforismos y Epidemias, con más de diecisiete citas de los primeros y diecinueve de las segundas.

Se ha visto que el anónimo autor de los Aforismos tomó muchos pasajes de nuestro escrito, al que hay que tomar como fuente, no como copia, por razones textuales y estilísticas. Pero en ciertos casos no se sabe bien cuál es el original y cuál la imitación ${ }^{4}$.

Con los libros de las Epidemias tiene también gran semejanza, especialmente por la presencia de la teoría según la cual el transcurso anormal de las estaciones del año produce numerosas afecciones epidémicas.

Por esta y otras razones nuestro escrito puede fecharse a comienzos del siglo Iv a. C.

Conocido y citado por Diocles de Caristo, fines del siglo iv, fue posteriormente leído y comentado por Galeno, Erotiano y Rufo de Éfeso.

\footnotetext{
2 Cf. J. A. López Férez, "Sobre el léxico de los Aforismos hipocráticos», Estudios Clásicos 87, 1984, pp. 91-98.

3 Cf. Tratados hipocráticos, II, Biblioteca Clásica Gredos, Madrid 1986. Entre otros tratados traduzco alli Sobre los humores, con introducción y notas (pp. 89 117).

K. Deichgräber, Hippokrates' De humoribus in der Geschichte der griechischen Medizin, Wiesbaden 1972.
} 
Galeno lo apreció sobremanera por tratar, siquiera fuera someramente, la cuestión de los humores, elementos esenciales en la fisiología galénica. El concepto de «humor» es fundamental para explicar la fisiologia, patología y el tratamiento en la obra de Galeno. Después, a través de Oribasio, ya en el siglo Iv d. C., y gracias a otros comentaristas, nuestro escrito llegó a la Edad Media, siendo recogido y explicado entre los musulmanes, especialmente por obra de Maimónides, ya en el siglo XII.

5. Por su contenido y estructura, Sobre los humores es el escrito más oscuro y enigmático de toda la Colección hipocrática ${ }^{5}$. Es una sarta de fragmentos tomados de (o por) otros escritos hipocráticos, dispuesta a veces en montón, sin orden ni concierto alguno.

Desde pronto fue considerado como un prontuario o memorándum (únoнvíната) sobre los puntos esenciales de la medicina hipocrática. En

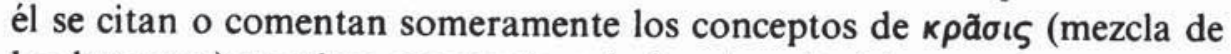
los humores) y крí, lución de las enfermedades; la teoría y práctica sobre purgas y evacuaciones; el pronóstico; la influencia del medio ambiente sobre el ser vivo; etc.

Para elaborar tal tratado su autor debió hacer un gran esfuerzo de sintesis, pero el resultado, a fuerza de concisión, es un contenido oscuro, inaccesible, e intraducible a nuestra lengua en numerosas ocasiones.

Jones ha visto la afición por lo raro y dificil en la literatura griega ${ }^{6}$, empezando por el estilo oracular caracterizado, como es sabido, por contestaciones ambiguas y, cuando menos, de doble interpretación. Heráclito, ciertos pasajes de los coros de Esquilo, algunas secuencias de Píndaro, por citar sólo unos ejemplos destacados, estarían presididos por el gusto hacia lo misterioso y enigmático. Licofrón, en su Alejandra, compuesta a comienzos del siglo II a. C., llegó al punto extremo de oscuridad sintáctica, léxica y estilística.

Con todo, no debemos pensar que Sobre los humores fuera escrito para una sociedad secreta o cerrada tal como lo fueron, quizá, otros libros hipocráticos como Sobre la decencia, Juramento y Preceptos. Más adecuado es ver en el estilo de nuestro escrito algo grato para una audiencia o grupo esotérico que hablaba y se entendía en clave, o sea, gentes comprometidas a guardar silencio sobre lo que oían, como era el caso de los pitagóricos, y a no propalar lo que sabían o veían, al modo de los iniciados en los misterios órficos.

\footnotetext{
5 Véase la edición de W. H. S. Jones, Hippocrates, IV, Cambridge (Mass.) Londres 1967 (= 1931), pp. XVII-XXI y XXX-XXXII

- En la obra citada, pp. IX-XII, bajo el epigrafe "Oscuridad intencionada en escritos antiguos".
} 
6. Empecemos por los problemas de estructura y composición. El capitulo II nos sorprende con un "debe observarse lo siguiente» que muy bien podríamos considerar el comienzo del libro, pues el catafórico таũтa («lo que sigue», "lo que viene después») da pie suficiente para mantener tal hipótesis. Además, tal proceder viene avalado porque los capítulos primero y último de nuestro tratado parecen constituir añadidos posteriores colocados al comienzo y final del rollo de papiro en que estaria contenido nuestro escrito, por obra de alguien que no quería que se perdieran, o que pensó que tal lugar era el adecuado para insertar tales fragmentos. Tal sucede, en efecto, al comienzo y final de Preceptos, donde ambos extremos están totalmente desconectados respecto del contenido central.

7. Ahora bien, el mayor problema de nuestro tratado es la distribución sintáctica. Por su carácter aforístico y sentencioso Sobre los humores guarda una gran semejanza con Aforismos y Sobre el alimento. En los tres escritos, el contenido, oscuro en muchas ocasiones, se refleja en la expresión y forma literaria.

Cuando estudiamos los Aforismos ${ }^{7}$, advertimos que tales sentencias breves, de validez universal, pero aplicadas a situaciones y casos concretos, tienen mucho de autoridad, de enseñanza, de prestigio oculto y ritual. Es algo muy cercano a la máxima judicial o al refrán sentencioso. Hay mucho del saber popular, sólo que elevado a la categoría cientifica y literaria. Pero en tales construcciones aforísticas abundan los recursos propios de la lengua hablada: anacolutos, cambios bruscos de sujeto, omisión del sujeto sin previa advertencia, oraciones nominales puras, asíndeton entre oraciones y entre miembros de la oración, abuso de demostrativos anafóricos y catafóricos, etc.

En Sobre los humores hay varios pasajes en que las palabras se amontonan sin nexo alguno que las distribuya, ordene, coordine o subordine. La falta de referencias e indicadores de distribución, de precisiones adjetivales, de partículas de unión, de calificadores de extensión y manera, asi como la parquedad absoluta de sustantivos y verbos hacen, muchas veces, punto menos que incomprensible el conjunto.

8. Otro problema lingüístico especialmente agudo en este tratado es el léxico. Vocablos mal integrados en campos semánticos definidos; hápax legómena; términos tardíos; otros ni siquiera recogidos en diccionarios especializados; etc.

9. Hemos pensado que sería de alguna utilidad ofrecer los pasajes más relevantes de tal tratado, en la citada edición de Jones, y destacar

' En Tratados hipocráticos, I, Madrid 1983, p. 228 ss. 
al hilo de la lectura ese cúmulo de problemas, especialmente de indole sintáctica y léxica.

Y bien, el capitulo I comienza así: «El color de los humores, donde hay reflujo de ellos, es como el de las flores. Hay que conducirlos por la parte apropiada hacia la que se inclinan, salvo aquellos cuya cocción acontece en el momento oportuno.»

Para comprender este pasaje nada mejor que recordar algunas notas generales de los humores. En primer lugar, con el término xupós se alude, a veces, en el $C$. $H$. a sustancias líquidas de diversa índole: jugos, zumos, savia, etc. El vocablo está relacionado etimológicamente con el verbo $\chi \hat{\varepsilon} \boldsymbol{\omega} \omega$ 'verter', 'derramar'. El plural se refiere a los elementos liquidos, fluidos, que se mueven dentro del cuerpo en varias direcciones, aunque sea lentamente. Dentro del $C$. $H$. no hay un sistema coherente que abarque todos los humores en sus distintas manifestaciones. Tanto se nos habla solamente de dos (bilis-flema), sistema binario de opuestos, según lo que era normal en el pensamiento arcaico griego, polar y antitético, como se nos ofrece un cuadro más completo de cuatro humores (bilis amarilla-flema-sangre-bilis negra), que difieren entre si en razón de su color (desde el blanco de la flema hasta el negruzco de la bilis negra) y calor (por ejemplo, fría es la flema, pero la bilis es caliente).

En cuanto a que «el color de los humores es como el de las flores", estamos lejos de saber exactamente qué se quiere decir con ello. Ya Galeno nos habla de varias maneras de entender el pasaje: suponer que los humores, tal como las flores, tienen un color propio; creer que el color de los humores es florido, es decir, de bella apariencia; pensar que interesa estudiar el color de los humores antes que se retiren al interior del cuerpo, momento en que el aspecto exterior de nuestro físico queda reseco como una flor sin savia. No estamos seguros de qué explicación prefería Galeno. Los comentaristas antiguos y modernos guardan silencio en este punto.

Sobre el reflujo (ă $\mu \pi \omega \tau \iota \varsigma)$ también nos encontramos con un escollo de léxico. Se trata de un vocablo que había sido utilizado ya por Heródoto (por ejemplo en II 11) para referirse al reflujo del mar. Está claramente relacionado con el verbo nívw; con distinto grado vocálico, semejante al que hallamos en nuestro término, está $\pi \tilde{\omega} \mu a$ 'bebida'. El sustantivo ă $\mu \pi \omega \tau \iota \varsigma$ alude al reflujo de la sangre y de otros humores desde la superficie hacia el interior del cuerpo.

Pasando adelante con nuestra traducción (en la edición de Jones, I, línea 5): «Prudencia. Inexperiencia. Dificultad en la experiencia. Calvicie. Vacuidad de las vísceras; para las de abajo, plenitud; para las de arriba, alimento. Tendencia hacia arriba, tendencia hacia abajo. Los 
movimientos espontáneos hacia arriba y hacia abajo, tanto los que benefician como los que perjudican.»

Desde el punto de vista sintáctico, ¿a quién se refieren "prudencia» e «inexperiencia»? Podemos admitir, por el sentido general, que no por el contexto, que es un consejo al médico o estudiante de medicina: que tenga experiencia, que evite la inexperiencia, que tenga en cuenta lo dificultoso que es adquirir la experiencia. Este punto ya llamó la atención de varios escoliastas helenísticos, que opinan, porque no lo entendieron bien, que anzıрín era la inmensidad de la medicina, es decir, la tomaban

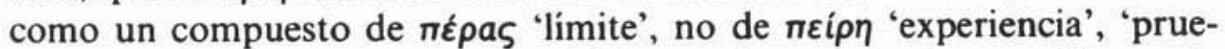
ba'. El término que nos permitiría resolver toda la cuestión sería

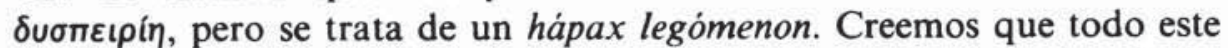
pasaje debe referirse a la necesaria experiencia que el médico ha de tener al abordar el dificil tema de los humores, pero, como hemos visto, no faltan problemas léxicos y sintácticos. En efecto, esas palabras, dispuestas asindéticamente, no nos dicen nada de su relación mutua; no forman frase alguna, ni sugieren ninguna pauta de anterioridad, simultaneidad o posterioridad; ni de causa a efecto; ni de mayor a menor.

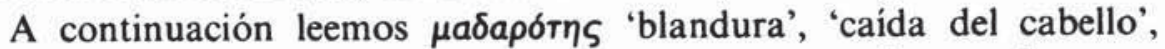
pero puede significar también 'humedad'. Los comentaristas andan confusos. Jones propone leer $\pi \lambda а \delta а \rho \delta ́ т \zeta \varsigma$ 'flaccidez', y entenderlo con el genitivo siguiente que sería un genitivo subjetivo 'flaccidez de las cavidades'. Nótese que el propio Jones mantiene tal opinión sólo en la nota correspondiente, pero no se atreve a introducir sus especulaciones en el texto.

Otro singular escollo tenemos en oriáyxva, término usado desde Homero para designar las «vísceras» (corazón, pulmones, hígado, riñones); las "entrañas", de forma imprecisa, como asiento de los sentimientos. Aquí puede aludir a tales vísceras, pero también metafóricamente a la cavidad en la que se alojan las mismas. Si puntuamos de diversa manera (es sabido que los textos griegos eran escritos en forma continua, sin puntos ni comas), al modo que Jones sugiere, podríamos entenderlo así: "flaccidez de las vísceras: vacuidad en las de abajo; plenitud en las de arriba". Pero, en tal caso, queda suelto троф⿰ं 'alimento'. Por todo ello, Jones, aunque da en oportuna nota tal lectura, mantiene el texto recibido, tal como lo edita Littré.

Más abajo, «tendencia hacia arriba, tendencia hacia abajo» hemos de referirlo a los humores, pero ello lo deducimos de otros contextos en donde de forma explícita se nos dice que el médico ha de conocer los movimientos peculiares de los humores en cada enfermo, pues no en todos funcionan igual. Precisamente, al ver a determinado enfermo y sa- 
biendo cómo es la marcha y movimiento de los humores dentro del mismo, el médico actuará en una línea determinada, procurando provocar o alterar el curso normal de los humores con fines terapéuticos. Es

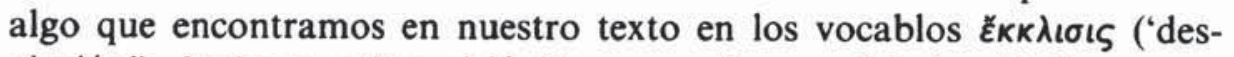

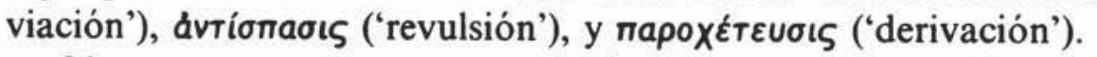

Nos encontramos ante tres términos que son muy difíciles de precisar partiendo de los datos del $C$. $H$., pues en ningún contexto encontramos bien definida la terapia que debe seguirse en caso de trastornos en el funcionamiento de los humores. Las explicaciones que obtenemos, especialmente gracias a Galeno, están teñidas de teorías y lucubraciones posteriores.

La desviación ( $\left.\tilde{\varepsilon}_{\kappa \kappa} \lambda \iota \sigma \iota \varsigma\right)$ consiste en encaminar y dirigir los humores por un determinado camino siguiendo normas terapéuticas. La revul-

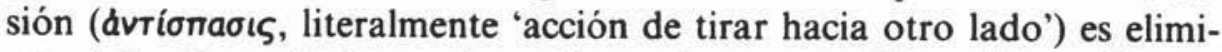
nar el funcionamiento morboso de un órgano o tejido a fuerza de castigar otra parte del cuerpo, bien mediante una sangría, bien con un esfuerzo extraordinario y fatigoso en sumo grado. Está basada en el método alopático (contraria contrariis curantur) y hallamos suficientes datos en el $C$. $H$. para hacernos una idea aproximada de en qué consistía.

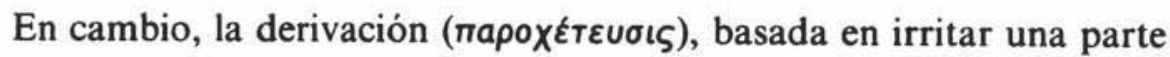
sana para aliviar la enfermedad, es un método terapéutico poco utilizado en el $C$. $H$. y nos resulta dificil de precisar por la falta de suficientes contextos.

10. En el capítulo II leemos: «Debe observarse lo siguiente: las afecciones que terminan espontáneamente, o, por ejemplo, en el caso de las flictenas que surgen tras las quemaduras, en qué condiciones y cuáles son las que perjudican o benefician; posturas, movimiento, exaltación, postración, sueños, vigilia.» Todos los nominativos funcionan

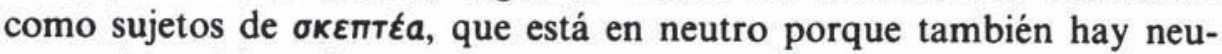
tros sujetos. En todo caso es interesante el cúmulo de sustantivos, muy del tono general de esta obra.

Más abajo encontramos veintiséis sustantivos sin nexo, en mezcolanza total: «Información sobre vómito, evacuación por abajo, esputo, mucosidad, tos, eructo, hipo, flato, orina, estornudo, lágrimas, picores, cosquillas, tactos, sed, hambre, repleción, sueños, dolores, falta de dolor, cuerpo, inteligencia, saber, memoria, voz, silencio.» Suponemos que esa información hace referencia a la que debe tener un médico. Pero los editores no están de acuerdo al respecto. Así, Littré traduce: «étudier les vomissements...».

11. Igual sucede en capitulos III y IV. En III tenemos asi: «Purga- 
ciones en las enfermedades de la matriz; vómitos violentos por arriba, que producen cólicos y son grasientos, sin mezcla, espumosos, calientes, mordicantes, herrumbrosos, variopintos, parecidos a raspaduras, con aspecto de heces, sanguinolentos, sin flatos, crudos, cocidos, secos; todo lo que fluye alrededor, observando si el enfermo se encuentra bien o mal, antes que haya peligro; de qué tipo es lo que no debe cesar.»

Suponemos que todo este capitulo debe referirse al «debe observarse» del anterior. Obsérvese la riqueza de matices en los vómitos, con nada menos que dieciséis clases, expuestas mediante una preciosa mezcla de predicados: participios neutros en presente, adjetivos en - $\omega \delta \eta \varsigma$, , con otros morfemas; bien afirmativos, bien negativos ('sin mezcla', 'sin espuma', 'sin flato').

En IV, línea 5, tenemos: "La postración, sequedad, firmeza, respiración agitada, hipocondrio, extremidades, ojos enfermos, cambio de color, pulsaciones, enfriamientos, palpitaciones, durezas de la piel, de los nervios, de las articulaciones, de la voz, del entendimiento; postura voluntaria; cabellos; uñas; la facilidad, o no, de soportar lo que es preciso.»

Hallamos una larga enumeración de quince sustantivos; el duodéci-

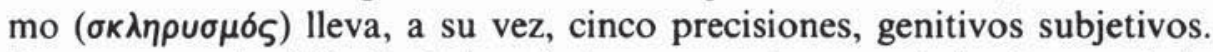
Pensemos en la dificultad de relacionar oportunamente la dureza de la piel con la del entendimiento en tal secuencia, cuando andamos faltos de contextos semejantes que permitieran darnos alguna luz al respecto. Pero lo llamativo del caso es que tras una enumeración de nominativos (IV, lineas 1-4) pasamos al acusativo. El nominativo con función enumerativa es algo normal en sintaxis griega, desde las mismas tablillas micénicas. Mas estos acusativos no pueden explicarse por régimen sintáctico alguno, ni siquiera por perseverancia de un esquema sintáctico próximo. Tenemos dos acusativos seguros ( los cinco siguientes son neutros y no permiten, por tanto, tomar una decisión sobre si son nominativos o acusativos; pero lo que sí queda claro es que a continuación tenemos otra vez nominativos.

Curiosa es la enumeración de IV, línea 10 , donde tras «señales son éstas: olores...» tenemos diez sustantivos en asíndeton.

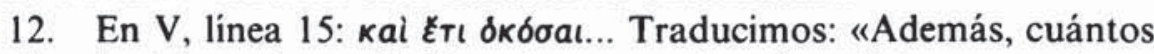
son los depósitos de condición tal que resultan beneficiosos, gracias a los alimentos sólidos, bebidas, olores, espectáculos, conciertos, pensamientos, evacuaciones, calentamiento, enfriamiento, sustancias húmedas, sustancias secas, humedecer, secar, unturas, ungüentos, parches, emplastos, polvos, vendajes, epitemas, posturas, fricciones, tranquilidad, esfuerzo, reposo, sueño, vigilia, flatos desde arriba o desde abajo; recur- 
sos generales, particulares, hechos con artificio; en momentos en que no se dan los paroxismos ni se van a producir; tampoco con pies fríos, sino cuando la enfermedad declina.» Observamos aquí un catálogo largo y diverso donde tras «benefician" ( $\left.\dot{\phi} \varepsilon \lambda \hat{\varepsilon} \varepsilon_{0} \cup \sigma \iota\right)$ vemos en mezcolanza dativos instrumentales (once), más dos infinitivos limitativos, más otros siete dativos, más siete nominativos, más otro dativo con dos precisiones adverbiales, más tres adjetivos también en dativo (los editores no se ponen de acuerdo con qué concuerdan o a qué se refieren); más tres dativos locativos temporales.

13. Para acabar hemos creido conveniente traducir un bonito capitulo, el noveno, en donde podemos leer así:

«Respecto al espíritu: falta de moderación en bebidas y comidas, en el sueño y en la vigilia; además, la resistencia ante las fatigas, causada por ciertas pasiones, como la de los dados, o por mor de la profesión, o por la necesidad; en qué fatigas esa resistencia se presenta ordenada o desordenada. Los cambios: desde qué situaciones y hacia qué otras ocurren.

En relación con las costumbres: laboriosidad del espíritu, cuando una persona investiga, se preocupa, ve, habla y otras cosas por el estilo, como tristezas, arrebatos de cólera y deseos. Las aflicciones del espíritu causadas por un encuentro fortuito, o las originadas por la vista o el oído.

Cómo actúan los cuerpos: cuando una muela rechina, los dientes padecen dentera; a quien pasea a lo largo de un precipicio le tiemblan las piernas; cuando uno levanta con las manos lo que no debe, éstas tiemblan; una serpiente, vista de repente, produce palidez.

Miedos, vergüenza, pena, placer, cólera y otros sentimientos por el estilo; de esa forma responde a cada uno de ellos la correspondiente parte del cuerpo en su actuación; en tales ocasiones, se producen sudores, palpitaciones del corazón y reacciones parecidas.»

Como podemos comprobar se trata de un capítulo muy importante con agudas observaciones sobre la falta de moderación en comidas, bebidas y sueño; la resistencia ante las fatigas; el trabajo espiritual que se despliega cuando uno investiga o está preocupado por algo; la tristeza fortuita, etc. Son todos ellos temas propios de la Psicología general y de la Antropología, muy de actualidad en nuestros días.

Hasta aquí llegan nuestras observaciones sobre unos cuantos capítulos de Sobre los humores. Vemos con cuántas dificultades lingüísticas, aparte de las de contenido y las estrictamente médicas, se enfrenta el filólogo que trata de comprender esos venerables textos. Los mayores problemas son de tipo léxico y sintáctico. Aparte, los relativos a la críti- 
ca textual, verdadera mezcla y resumen de todo lo que llevamos diciendo.

En el entendimiento y esclarecimiento de los textos médicos griegos creemos que el filólogo y el lingüista tienen un buen campo de estudio, en unión con el estudioso de la historia de la medicina y con el filósofo.

Juan Antonio López Férez 